\title{
Kualitas Ruang Terbuka Hijau dan Potensi Pariwisata Kreatif di Taman Indonesia Kaya, Kota Semarang
}

\author{
Eko Setyo Widyonarso $^{1 *}$, Fadjar Hari Mardiansjah ${ }^{2}$ \\ ${ }^{1}$ Magister Pembangunan Wilayah dan Kota, Departemen Perencanaan Wilayah dan Kota, \\ Fakultas Teknik Universitas Diponegoro, Semarang Indonesia \\ Email: eswidn@gmail.com
}

Received 03 Desember 20219; Reviewed 29 April 2020; Accepted 12 Juni 2020

Journal Homepage: http://jurnal.borneo.ac.id/index.php/borneoengineering

DOI: https://doi.org/10.35334/be.v4i1.1099

\begin{abstract}
Along with the increasing density of the city that shifts green space, urban parks ultimately become the only place for urban communities to feel the connection to nature. Therefore, it is important to have a good quality city park. City residents opinions about the factors that encourage visitors to visit city parks are also important as input and evaluation for city park providers. On the other hand, there is potentially given by city parks other than just as a place for recreation and relaxation. Therefore, this study wants to show how the quality of city parks, the factors which make visitors come to city parks, and what kind of potential can be achieved from city parks. This research was conducted and presented in a descriptive-qualitative form in order to provide a complete picture of the phenomena that occur in city parks. The results obtained are that TIK has a good quality park, able to attract visitors, and has the potential for creative tourism.
\end{abstract}

Keywords: city parks, the potential for creative tourism, the quality of green open space

\begin{abstract}
Abstrak
Seiring dengan semakin meningkatnya kepadatan kota yang menggeser ruang hijau, taman kota pada akhirnya menjadi satu-satunya tempat bagi masyarakat perkotaan untuk merasakan koneksi kepada alam. Oleh karena itu, penting untuk memiliki taman kota yang berkualitas baik. Pendapat warga kota mengenai faktor yang mendorong pengunjung untuk mengunjungi taman kota juga penting agar menjadi masukan dan evaluasi bagi penyedia taman kota. Di sisi lain, ada potensi yang diberikan oleh taman kota selain hanya sebagai tempat pengujung berekreasi dan bersantai. Oleh karena itu, penelitian ini ingin menunjukkan bagaimana kualitas taman kota, faktor apa yang membuat pengunjung datang ke taman kota, dan potensi apa yang bisa diraih dari taman kota. Penelitian ini dilakukan dan disajikan dalam bentuk deskriptif-kualitatif agar dapat memberikan gambaran yang lengkap mengenai fenomena yang terjadi di taman kota. Hasil yang didapatkan adalah bahwa TIK telah berkualitas baik, mampu menarik pengunjung, dan memiliki potensi pariwisata kreatif.
\end{abstract}

Kata kunci: kualitas ruang terbuka hijau, potensi pariwisata kreatif, taman kota,

\section{Pendahuluan}

Sebuah kota tetap menjadi lingkungan yang menegangkan bagi tiap warga kota karena gaya hidup yang sibuk, konsentrasi populasi, kebisingan dan polusi udara. Ditambah tren warga kota sekarang 
mengalami peningkatan urbanisasi yang signifikan semenjak 2010 dan akan terus meningkat, $60 \%$ di 2030 (Wendel, Zarger, \& Mihelcic, 2012), 80\% di 2050 (Sirina, Hua, \& Gobert, 2017a; UN DESA, 2013), dan 70\% hingga 2150 (Sturiale \& Scuderi, 2018). Peningkatan kepadatan dan kesan hidup di daerah perkotaan dari yang ramai menjadi semakin ramai lagi tentu akan mempengaruhi tatanan sosial suatu kota dan dapat menciptakan tekanan psikologis. Dalam konteks ini, kebutuhan luar ruangan terutama pariwisata (wadah tempat untuk leisure dan rekreasi) dan permintaan akan ruang hijau di kota pastinya meningkat pesat karena manfaat yang mereka sediakan (Zhang, 2014; Sirina et al., 2017; Romolini et al., 2019). Kebutuhan warga kota untuk pengalaman lingkungan (environmental experience) adalah alasan yang signifikan taman kota sebagai sumber daya penting membentuk keterikatan tempat (place attachment), ikatan sosial antara orang dan lingkungan di sekitar mereka (Giuliani, 2003). Pada akhirnya, taman kota menjadi satu-satunya tempat bagi masyarakat perkotaan untuk merasakan koneksi kepada alam (Kabisch, 2015). Menilik hal tersebut, maka, keberadaan taman kota menjadi sangat vital dalam perencanaan perkotaan.

Taman kota memberikan manfaat yang sangat baik bagi pengunjung maupun lingkungan di sekitarnya. Dalam skala perkotaan, taman kota adalah bagian dari ruang hijau, sebagai peredam panasnya perkotaan dan urban heat island, serta sebagai tempat bagi warganya untuk melakukan leisure, berekreasi, berolahraga, hingga bersosialisasi (Nath, Zhe Han, \& Lechner, 2018). Bagi pengunjung, ruang hijau yang termasuk di dalamnya adalah taman kota penting sebagai tempat untuk menyeimbangkan kehidupan kota yang hectic sehingga dapat menurunkan kelelahan mental dan stress, membantu mengurangi efek negatif secara psikologis dari hidup dan bekerja di kota yang padat akan bangunan (Nath, Zhe Han, \& Lechner (2018). Taman sebagai ruang publik juga mempromosikan kesehatan untuk semua orang (Sia, Kua, \& Ho, 2020). Artinya, taman mendorong adopsi oleh masyarakat perkotaan gaya hidup sehat dan aktif. Taman kota memberikan manfaat rekreasi seperti kesempatan untuk terlibat dalam olahraga, termasuk praktik rutin kegiatan fisik, bersantai, bertemu orang lain, membina interaksi sosial atau hanya pengalaman dengan alam. Akhirnya, ruang hijau perkotaan memungkinkan kesempatan pada pengalaman belajar tentang lingkungan alam.

Dalam beberapa tahun terakhir, orientasi perencanaan kota memasukkan dan/atau meningkatkan infrastruktur hijau khususnya "taman perkotaan" sebagai salah satu unsur perkotaan yang telah menarik perhatian dan tumbuh dalam literatur beberapa tahun terakhir (Kabisch, 2015; Drilling, Giedych, \& Poniży, 2016; Sturiale \& Scuderi, 2018; Ayala-Azcárraga, Diaz, \& Zambrano, 2019). Dempsey dan Burton (2012) mengemukakan bahwa perencanaan taman modern juga mengingatkan tujuan para reformis sosial abad ke-19 dan ke-20 yang berupaya memastikan lingkungan hidup yang berkualitas baik bagi penduduk kota. Meskipun perhatian meningkat untuk taman perkotaan dalam literatur ilmiah, potensi inklusi mereka dalam perencanaan perkotaan belum dilihat sebagai elemen strategis untuk pembangunan yang berkelanjutan dan model kota yang menerapkan sosial inklusif (Sturiale, Scuderi, Timpanaro, Foti, \& Stella, 2020). Padahal taman kota berdasarkan manfaat yang disebutkan sebelumnya memiliki potensi menciptakan aktivitas masif masyarakat untuk kolaboratif menata kembali ruang publik kota sebagai aset di masa mendatang.

Selain itu, taman kota juga mempunyai banyak potensi lain, diantaranya adalah pariwisata kreatif. Semakin berkembangnya zaman, maka akan banyak aktivitas dalam bentuk berbagai event yang membutuhkan wadah agar dapat dilaksanakan. Taman sebagai bagian dari ruang terbuka publik menjadi salah satu bagian yang bisa menjadi lokasi dilaksanakannya event tersebut. Keberadaan 
event yang dilaksanakan secara jelas dan teratur akan semakin menarik pengunjung untuk beraktivitas di ruang terbuka.

Begitu pentingnya taman kota bagi perkotaan, maka penting bagi peneliti untuk memastikan bahwa taman kota yang ada telah memiliki kualitas yang baik, setidaknya secara fisik. Di sisi lain, penting untuk mengetahui apa yang membuat pengunjung ingin mengunjungi taman kota sebagai bentuki evaluasi bagi penyedia taman kota khususnya Pemerintah Kota. Selain itu, perlu untuk melihat bagaimana potensi dari taman kota itu sendiri untuk di masa yang akan datang. Maka, penelitian ini ingin melihat bagaimana kualitas ruang hijau taman kota, apa saja faktor yang mempengaruhi akses ke taman kota, dan bagaimana potensi yang ada pada taman kota tersebut.

\section{Lokasi, Metode Penelitian, dan Metode Pengumpulan Data}

Penelitian ini dilakukan di Taman Indonesia Kaya. Taman Indonesia Kaya merupakan bentuk csr dari Djarum Foundation, sehingga pengelolaannya dikelola bersama antara pemerintah dan swasta. Sebelum menjadi Taman Indonesia Kaya, taman ini bernama Taman Menteri Supeno atau sering disebut sebagai Taman KB (Keluarga Berencana). Lokasi tersebut dipilih karena Taman Indonesia Kaya berada di lokasi yang strategis di pusat perkotaan dan dekat dengan perkantoran dan pusat perbelanjaan, memiliki pengunjung dengan karakteristik yang beragam, memiliki fasilitas yang cenderung lebih lengkap daripada taman lainnya di Kota Semarang, dan sering menjadi lokasi berlangsungnya berbagai jenis event kebudayaan di Kota Semarang.

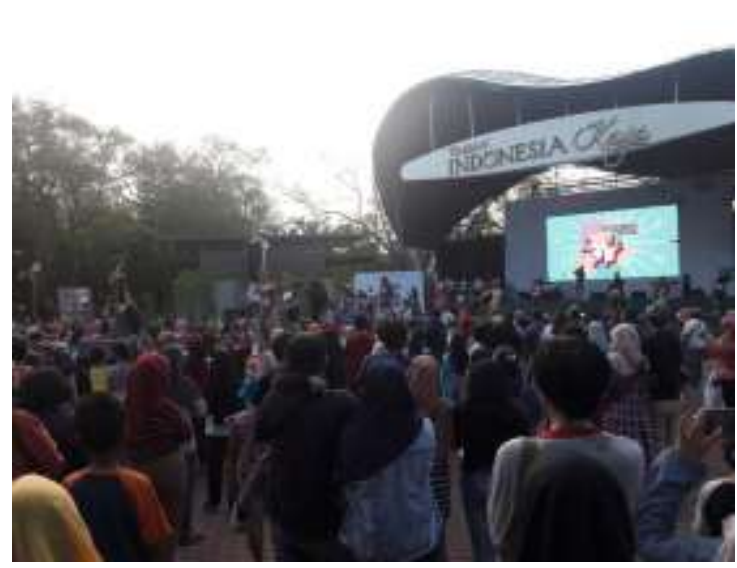

$a$.

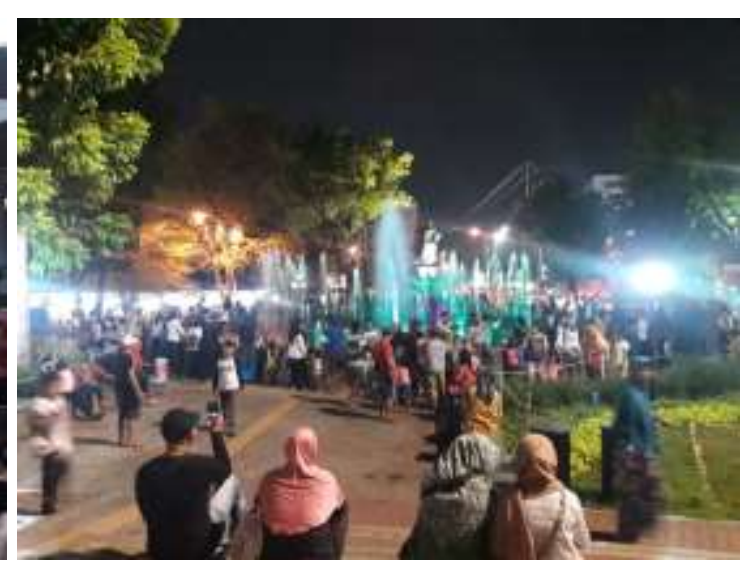

b.

Gambar 1. Kondisi Keramaian TIK: (a) di siang hari dan (b) di malam hari

Penelitian ini merupakan penelitian kualitatif, demi mendapatkan hasil yang lebih dalam mengenai manfaat yang dirasakan oleh pengunjung. Data dikumpulkan dengan metode purposive sampling, yaitu kepada pengunjung berusia remaja, muda, keluarga yang memiliki anak yang masih kecil, orang tua, dan pengelola taman. Penelitian ini dilakukan dengan menyebarkan wawancara kepada para pengunjung dan observasi terhadap taman secara menyeluruh. Hasil yang ditemukan dijelaskan dalam subbab hasil temuan penelitian. 


\section{Hasil dan Pembahasan}

\subsection{Kualitas Ruang Hijau/Taman Kota}

Melihat kualitas ruang hujau taman kota dapat dilihat dari bagaimana elemen fisik tamannya, yaitu ketersediaan fasilitas, kondisi fasilitas, ketersediaan vegetasi, dan aksesibilitas (Frick, 2006). Di sisi lain, kualitas ruang hijau perkotaan dalam penelitian Nath, Zhe Han, \& Lechner (2018) ditentukan oleh kemudahan visual taman. Maka, penting untuk melihat aspek visual taman dalam menentukan kualitas ruang hijau.

TIK memiliki berbagai fasilitas, yaitu panggung budaya dengan total kapasitas panggung 1000 orang, Taman Pandawa Lima, Pelataran Penikmat Seni, amphiteater, area hijau, gerbang mural, air mancur menari yang menyala setiap hari pada pukul 19.00-20.00 pada hari kerja dan 19.00-21.00 pada akhir pekan, ruang ganti penampil, toilet, keran air minum. Fasilitas tesebut sangatlah lengkap untuk sebuah taman. Walaupun TIK memiliki beragam fasilitas, namun oleh karena maintenance yang dilakukan sangat intensif membuat fasilitas yang ada selalu terawat dengan baik. Keberadaan petugas bersih-bersih dan petugas perawat taman membuat kebersihan TIK selalu terjaga dan tanaman yang beragam selalu terawat dengan baik. Selain itu, terdapat petugas yang menjaga keamanan TIK selama 24 jam serta adanya kelengkapan kamera pengawas membuat TIK menjadi aman dan tidak mudah bagi pengunjung untuk melakukan vandalisme maupun aktivitas yang mengganggu pengunjung lain.

Ketersediaan vegetasi memberikan manfaat berupa rasa sejuk bagi pengunjung, manfaat kesehatan, dan manfaat sosial. Sirina, Hua, \& Gobert (2017) menunjukkan bahwa kunjungan ke taman kota memiliki konsekuensi kesehatan yang signifikan terutama untuk pengguna taman yang lebih tua, 50 tahun lebih. Ketersediaan vegetasi di TIK sangat beragam dan sangat terawat. Vegetasi di TIK terawat dengan baik karena taman ini selain dilengkapi dengan penjaga taman juga dilengkapi dengan petugas bersih-bersih dan petugas yang merawat tanaman dan pepohonan. Hanya saja, beberapa tanaman hias mungkin jenisnya harus disesuaikan lagi (diganti) atau ekstra dirawat karena butuh air yang banyak atau tidak tahan dengan cuaca panas yang meningkat ekstrem. Sejarah panas tertinggi Kota Semarang berdasarkan BMKG tercatat 22 Oktober 2019 mencapai rekor baru $39.4{ }^{\circ} \mathrm{C}$, yang sebelumnya 12 Oktober 1972 dan 18 Oktober 2002 mencapai $38.5^{\circ} \mathrm{C}$ dan 13 Oktober 1972 mencapai $38.7{ }^{\circ} \mathrm{C}$. Kondisi negara yang termasuk dalam iklim tropis di tengah fenomena perubahan iklim dan peningkatan dampak pulau panas perkotaan (Urban Heat Island/UHI) menjadi tantangan tersendiri dalam menyediakan vegetasi khususnya tanaman hias yang tidak rentan dengan cuaca ekstrem. Selain itu menjadi tantangan tersendiri apabila dikaitkan dengan urbanisasi yang meningkat dengan kebutuhan masyarakat untuk ruang publik/ruang hijau dan rekreasi yang meningkat, misalnya pada penggunaan siang hari. TIK dan beberapa taman di Kota Semarang akan terlihat sepi di hari kerja terutama pada pukul 11.00-14.00 WIB.

Akses menuju TIK sangat mudah karena letaknya yang berada di pusat aktivitas Kota Semarang. Untuk menuju TIK, pengunjung dapat menggunakan angkutan umum berupa Bus Rapid Transit (BRT). Zona parkir juga disediakan bagi pengunjung yang ingin datang menggunakan kendaraan pribadi. Akan tetapi, zona dan tarif parkir mungkin akan berubah sesuai dengan event yang ada di TIK. Adanya zona dan tarif parkir yang tidak konsisten kerapkali membuat pengunjung kecewa.

Secara visual, TIK mampu memberikan visual yang indah selama 24 jam. Di pagi hingga sore hari, pengunjung dapat menikmati vegetasi dan hewan yang beragam, keberadaan mural wall dan adanya beberapa landmark di Taman berupa patung dan air mancur. Di malam hari, disajikan pencahayaan yang temaram di sepanjang taman, air mancur yang diberikan iluminasi cahaya, dan beberapa lampu sorot. Yang paling menarik pengunjung adalah keberadaan air mancur 
beriluminasi cahaya di malam hari akhir pekan. Pengunjung baik remaja, muda-mudi, hingga keluarga yang memiliki anak berusia dini seringkali ditemukan menunggu air mancur beriluminasi cahaya selain untuk menikmatinya, juga untuk mengunggahnya di media sosial dan bermain bagi anak-anak. Secara historis, motivasi yang paling umum untuk menghadiri event dan festival atau dalam hal ini pengalaman berbasis iluminasi pencahayaan adalah untuk alasan sosial (Andrew, 2014), dalam menciptakan ruang masyarakat untuk mengeksplorasi, pertukaran dan menghibur. Kegiatan berbasis iluminasi pencahayaan dan aktivitas seperti itu dapat mempromosikan kesempatan untuk integrasi sosial, keterlibatan dengan satu sama lain dan masyarakat dan integrasi norma sosial.

Keberadaan kualitas fisik taman yang baik dan bervisual yang indah membuat pengunjung datang dengan tujuan tidak hanya untuk melakukan satu jenis aktivitas. Pengunjung remaja dapat berkunjung untuk berekreasi, bersosialisasi, sembari menikmati alam, mengunggah aktivitas ke media sosial, mengunjungi event, ataupun menikmati visualisasi iluminasi cahaya dari air mancur. Pengunjung pasangan suami istri yang memiliki anak kecil mengunjungi taman tidak hanya untuk bersantai dan berekreasi, namun juga untuk mengajak anak bermain di air mancur. Orang tua tidak hanya berjalan dan menikmati alam, namun juga bersantai menikmati hiruk pikuk kegiatan dilakukan oleh pengunjung lainnya. Hal ini sesuai dengan pemahaman tentang apa yang merupakan hadiah pribadi dan sosial dari kunjungan taman telah berkembang dari waktu ke waktu sesuai dengan tren yang lebih luas dan ruang hijau perkotaan abad kedua puluh satu yang ditandai oleh multi-fungsinya (Sanesi dan Chiarello, 2006). Orang mengunjungi taman untuk berbagai motif yang mencakup aktivitas fisik yang relatif berat dan relaksasi dan refleksi yang lebih pasif. Pengunjung semakin termotivasi oleh pendidikan, sosialisasi, pencarian kesendirian, latihan hewan peliharaan, pelarian, persekutuan dengan alam dan kehadiran di acara-acara pribadi dan publik. Dengan memberikan latar belakang untuk spektrum kegiatan rekreasi seperti itu, taman secara umum setuju untuk berkontribusi pada kesehatan fisik dan psikologis penduduk kota dan pekerja (Bedimo-Rung et al., 2005; Coley et al., 1997; Conway, 2000 ; Matsuoka dan Sullivan, 2011; Ulrich dan Addoms, 1981; de Vries et al., 2003.

\subsection{Faktor yang mempengaruhi motivasi pengunjung ke taman kota}

Terdapat beberapa faktor yang mempengaruhi akses ke taman kota. Pertama, fasilitas yang lengkap dan beragam membuat pengunjung tertarik untuk berkunjung di TIK. Keberagaman fasilitas membuat beragamnya karakteristik pengunjung yang datang. Kedua, untuk menikmati alam. Beragamnya vegetasi yang ada di TIK serta adanya hewan-hewan liar seperti burung mendorong pengunjung yang suka dengan alam untuk berkunjung. Ketiga, untuk menikmati atraksi yang disediakan. Atraksi seperti air mancur warna-warni air mancur khusus untuk bermain anak-anak yang dinyalakan setiap akhir pekan, dan adanya event/festival/lomba yang dilaksanakan di panggung budaya dengan total kapasitas \pm 1000 orang dapat mendorong pengunjung untuk datang. Adanya fasilitas ruang yang mampu menampung pengunjung dalam jumlah besar memiliki potensi menciptakan aktivitas masif masyarakat untuk kolaboratif menata kembali ruang publik kota sebagai aset di masa mendatang (Sia et al., 2020). Event/festival yang pernah dilaksanakan di TIK diantaranya adalah festival kuliner, lomba menari, acara seni budaya, pertandingan musik, hingga event yang dilaksanakan organisasi kampus. Keempat, posisi taman kota sebagai ruang publik menjadi wadah pengunjung untuk bersosialisasi seperti bertemu dengan orang baru, tempat bertemu dengan teman-teman, dan keluarga. Kelima, untuk melarikan diri dari kesibukan pekerjaan. Oleh karena itu, TIK menjadi sangat ramai di akhir pekan dibandingkan dengan hari biasa. Keenam, pengunjung datang ke TIK untuk melakukan rekreasi dan bersantai. 


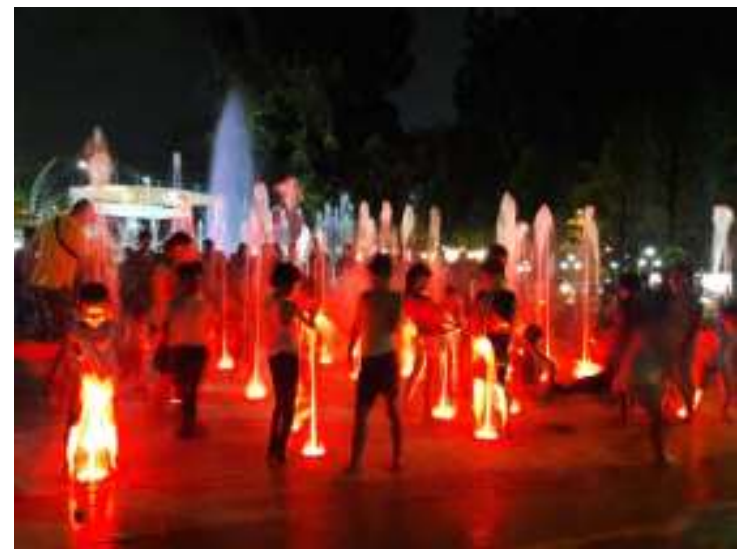

\section{Gambar 2. Anak-Anak Bermain di Air Mancur Warna-Warni}

Sesungguhnya, fasilitas untuk bermain anak menjadi temuan penting dalam penelitian ini. Tempat bermain untuk anak yaitu air mancur untuk anak bermain menjadi hal utama bagi pasangan muda yang memiliki anak untuk berkunjung ke TIK, diikuti dengan ikut menikmati air mancur, bersantai, dan rekreasi. TIK menyediakan ruang yang cukup untuk rekreasi (recreation) dan fasilitas santai/waktu luang (leisure) termasuk joging dan berjalan serta kesempatan bagi anak-anak untuk mengambil bagian dalam kegiatan fisik. Anak-anak diamati berlari, kejar-kejaran dengan temannya, dan bermain air basah-basahan dengan anak-anak seusianya. Hal ini penting untuk masa depan si anak, karena penelitian Nath, Zhe Han, \& Lechner (2018) melaporkan bahwa ada hubungan kuat antara kunjungan anak yang sering ke ruang hijau dengan sedang dipersiapkan untuk mengunjungi tempat-tempat yang serupa ketika dewasa. Hal ini sesuai dengan temuan dari inggris mengenai fasilitas di taman seperti taman bermain anak yang menyarankan bahwa anakanak memainkan peran penting dalam menyatukan orang-orang dan menciptakan peluang bagi orang tua di taman bermain untuk berinteraksi satu sama lain (Sia et al., 2020).

Di sisi lain, seiring dengan perkembangan digital, akses juga ditentukan oleh adanya media sosial dan website yang menyediakan ulasan dari pengunjung secara online. Media sosial merupakan bagian dari online customer reviews (OCRs), sedangkan OCRs sendiri merupakan bagian dari word of mouth (WOM) dalam bentuk modern. WOM secara signifikan mempengaruhi pembentukan sikap pengunjung dan niat berkunjung kembali (Xia \& Bechwati, 2008; Lee et al., 2009; Nguyen et al., 2018), dimana mereka meninjau komentar dari ulasan pengunjung yang sebelumnya bepergian ke destinasi dan itu membantu pengunjung baru S(Elwalda et al., 2016). Pengunjung cenderung selalu berbagi pengalaman dengan teman dan keluarga saat bepergian. Sosial media sangat membantu untuk menarik pengunjung dan promosi gratis bagi TIK. Pengunjung yang sebelumnya datang mempromosikan TIK secara langsung kepada orang di sekitarnya maupun melalui unggahan mereka di sosial media. Selain itu, keberadaan website pengukur kepuasan pengunjung cukup penting untuk menarik pengunjung baru. Misalnya, di mesin pencari google, TIK telah diulas sebanyak 8.311 kali oleh pengunjung, dengan nilai 4.6 dari skala 5.

Berdasarkan uraian di atas, maka faktor yang mempengaruhi motivasi pengunjung ke taman kota adalah fasilitas yang lengkap dan beragam, beragamnya vegetasi yang ada di TIK serta adanya hewan-hewan liar, keberadaan atraksi, fasilitas ruang yang mampu menampung pengunjung dalam jumlah besar, wadah pengunjung untuk bersosialisasi, untuk melarikan diri dari kesibukan pekerjaan, media sosial dan ulasan pengunjung di website tertentu. 


\subsection{Potensi Pariwisata di Taman Kota}

Taman kota dalam hal ini TIK merupakan tempat publik, sehingga dapat dikunjungi oleh siapa saja. TIK juga mempunyai kapasitas ruang yang besar untuk menampung berbagai event baik untuk pertunjukan budaya, untuk mengadakan berbagai lomba, hingga festival. Di sisi lain, keberagaman fasilitas di TIK mendorong pemanfaatan taman yang lebih beragam, dikombinasikan dengan adanya event-event pada akhirnya mendorong pada terciptanya kegiatan-kegiatan baru di seputar ekonomi kreatif. Fasilitas yang beragam dan multi kegiatan/event/festival diperlukan untuk memperpanjang lama tinggal masyarakat, berlama-lama berinteraksi, menumbuhkan minat dan motivasi berkunjung pada destinasi.

Pariwisata kreatif merupakan gabungan dari pariwisata dan ekonomi kreatif. Pendekatan hubungan ekonomi kreatif terhadap pariwisata menawarkan potensi untuk menambah nilai melalui pengembangan konten kreatif yang menarik dan pengalaman, mendukung inovasi dan membantu untuk membuat tempat yang lebih khas dan menarik melalui place-making. Industri kreatif didefinisikan sebagai kegiatan kreatif berbasis pengetahuan yang menghubungkan pemangku kepentingan, pengunjung dan tempat dengan memanfaatkan teknologi, untuk menghasilkan produk budaya yang bermakna, konten kreatif dan pengalaman. Mereka terdiri dari berbagai sektor, termasuk iklan, animasi, arsitektur, desain, film, game, gastronomi, musik, seni pertunjukan, permainan interaktif, dan televisi/radio. Tren saat ini di ruang-ruang publik di Asia terutama kota-kota Asia Pasifik abad ke-21 menunjukkan banyak perpaduan masa lalu dan sekarang atau membuktikan dirinya pada perilaku lokal (lokus genius kota-kota) dengan multibudaya dengan mengombinasikan bidang pariwisata kreatif, ekonomi kreatif dan teknologi mendunia yang tak terduga (Miao, 2001; Alwi, 2018; Richards, 2018).

Keberadaan destinasi wisata sebagai salah satu pendukung gerakan ekonomi mendorong pembuat kebijakan untuk terus mengembangkan potensi wisata yang ada. Sedangkan pada saat yang sama, tuntutan tumbuh untuk rekreasi luar ruangan untuk tempat bersantai dan aktivitas di waktu luang (leisure) bagi warga kota (citzens). Bahkan, terlihat gerakan dorongan kuat dan luas untuk mengubah sikap menggunakan kembali ruang-ruang kota yang tampak sunyi atau dilupakan dan yang sudah kurang dimanfaatkan. Karena berbagai desakan ini tidak heran apabila kota-kota di dunia, pemerintah daerahnya mendorong ide-ide kreatif, menghidupkan kembali taman kota, merevitalisasi kota lama, menata kawasan yang potensial untuk wisata gastronomi, menambah aktivitas, menambah lampu LED bahkan dikombinasikan fountain dengan tujuan menarik potensi besar citizens keluar menggunakan ruang publik terdekat untuk leisure, rekreasi bahkan wisata. Pemerintah daerah juga mulai menyadari potensi ruang kota yang dapat digunakan sebagai alternatif ruang terbuka publik seperti ruang di sepanjang sungai perkotaan untuk direvitalisasi dan dibangun taman-taman kreatif.

\section{Kesimpulan}

Penelitian ini telah mendiskusikan secara kualitatif bahwa kualitas ruang hijau taman kota dapat dilakukan dengan melihat elemen fisik taman, yaitu ketersediaan fasilitas, kondisi fasilitas, ketersediaan vegetasi, dan aksesibilitas (Frick, 2006) dan visual taman. TIK telah memiliki ketersediaan fasilitas yang sangat lengkap dan bahkan mampu menampung jumlah pengunjung dalam jumlah yang besar dan dengan kondisi yang baik. TIK juga telah memiliki vegetasi yang cukup dan beragam, walaupun perlu untuk mempertimbangkan jenis vegetasi yang lebih baik, mengingat bahwa suhu Kota Semarang dapat menjadi terlampau tinggi dan juga beriklim tropis. Akses menuju TIK juga sangat mudah karena dapat dijangkau dengan kendaraan umum maupun 
kendaraan pribadi, walaupun ketersediaan area parkir dan tarif yang sewaktu-watu berubah sesuai event yang ada. Secara visual, TIK mempu memberikan keindahan taman selama 24 jam, sehingga dapat dinikmati kapanpun. Maka, secara keseluruhan, kualitas ruang hijau taman kota di TIK telah baik. Namun, masih perlu ada peningkatan di beberapa sisi seperti pemilihan vegetasi yang lebih baik dan kejelasan mengenai akses parkir.

Kemudian, perlu untuk diketahui faktor apa saja yang mempengaruhi motivasi pengunjung ke taman kota. Faktor-faktor tersebut adalah fasilitas yang lengkap dan beragam, beragamnya vegetasi yang ada di TIK serta adanya hewan-hewan liar, keberadaan atraksi, fasilitas ruang yang mampu menampung pengunjung dalam jumlah besar, wadah pengunjung untuk bersosialisasi, untuk melarikan diri dari kesibukan pekerjaan, media sosial dan ulasan pengunjung di website tertentu. Fasilitas yang beragam dan multi kegiatan/event/festival adalah sangat penting untuk memperpanjang lama tinggal masyarakat, berlama-lama berinteraksi, menumbuhkan minat dan motivasi berkunjung pada destinasi.

Hal yang perlu diperhatikan bahwa ada potensi pariwisata pada taman kota yang perlu pengembangan. Maka, taman kota sebaiknya tidak hanya dilihat sebagai tempat rekreasi, melainkan juga dapat memberikan keuntungan ekonomi melalui pariwisata. Penelitian ini menyimpulkan bahwa TIK sebagai bagian dari ruang terbuka hijau yang juga merupakan ruang publik memiliki potensi pariwisata yang besar karena mampu menampung berbagai event, lomba, hingga festival. Terlebih, hal ini telah menjadi tren di negara-negara Asia (Miao, 2001; Alwi, 2018; Richards, 2018).

\section{Daftar Pustaka}

Alwi, N. M. (2018). Culture and Identity in Public Green Spaces: Story of Suropati and Menteng Park in Central Jakarta, Indonesia. In The IAFOR International Conference on Sustainability, Energy \& the Environment - Hawaii January 2018 (pp. 1-15). Hawaii: IAFOR The International Academic Forum.

Andrew, P. D. (2014). Lighting the Ultimate Tourism Experience: a case Study in Singapore. Auckland University of Technology.

Ayala-Azcárraga, C., Diaz, D., \& Zambrano, L. (2019). Characteristics of urban parks and their relation to user well-being. Landscape and Urban Planning, 189, 27-35. https://doi.org/10.1016/j.landurbplan.2019.04.005

Drilling, M., Giedych, R., \& Poniży, L. (2016). The idea of allotment gardens and the role of spatial and urban planning. In S. Bell, R. Fox-Kämper, N. Keshavarz, M. Benson, S. Caputo, S. Noori, \& A. Voigt (Eds.), Urban Allotment Gardens in Europe (pp. 35-61). London: Routledge. https://doi.org/10.4324/9781315686608

Frick, H. (2006). Arsitektur Ekologis : Konsep arsitektur ekologis di iklim tropis, penghijauan kota dan kota ekologis, serta energi terbarukan. Semarang: Penerbit Kanisius.

Giuliani, M. V. (2003). Theory of Attachment and Place Attachment. In M. Bonnes, T. Lee, \& M. Bonaiuto (Eds.), Psychological theories for environmental issues (pp. 137-170). London: Routledge. https://doi.org/10.4324/9781315245720

Kabisch, N. (2015). Ecosystem service implementation and governance challenges in urban green space planning-The case of Berlin, Germany. Land Use Policy, 42, 557-567. https://doi.org/10.1016/j.landusepol.2014.09.005 
Miao, P. (2001). Asia Public Places: Characteristics, Challenges, and Responses. In P. Miao (Ed.), Public Places in Asia Pacific Cities: Current Issues and Strategies (pp. 1-44). Dordrecht: The Netherlands: Kluwer Academic Publishers. https://doi.org/10.1007/978-94-017-2815-7

Nath, T. K., Zhe Han, S. S., \& Lechner, A. M. (2018). Urban green space and well-being in Kuala Lumpur, Malaysia. Urban Forestry and Urban Greening, 36(February), 34-41. https://doi.org/10.1016/j.ufug.2018.09.013

Richards, G. (2018). Cultural tourism: A review of recent research and trends. Journal of Hospitality and Tourism Management, 36, 12-21. https://doi.org/10.1016/j.jhtm.2018.03.005

Romolini, M., Ryan, R. L., Simso, E. R., \& Strauss, E. G. (2019). Visitors' attachment to urban parks in Los Angeles, CA. Urban Forestry and Urban Greening, 41(August 2018), 118-126. https://doi.org/10.1016/j.ufug.2019.03.015

Sia, A., Kua, E. H., \& Ho, R. (2020). Building Social Resilience Through Parks and Common Recreational Spaces. In C. Leong \& L. Malone-Lee (Eds.), Building Resilient Neighbourhoods in Singapore Advances in 21st Century Human Settlements (pp. 51-62). Singapore: Springer. https://doi.org/10.1007/978-981-13-7048-9_4

Sirina, N., Hua, A., \& Gobert, J. (2017a). What factors influence the value of an urban park within a medium-sized French conurbation? Urban Forestry and Urban Greening, 24(August 2016), 45-54. https://doi.org/10.1016/j.ufug.2017.03.021

Sirina, N., Hua, A., \& Gobert, J. (2017b). What factors influence the value of an urban park within a medium-sized French conurbation? Urban Forestry and Urban Greening, 24, 45-54. https://doi.org/10.1016/j.ufug.2017.03.021

Sturiale, L., \& Scuderi, A. (2018). The evaluation of green investments in urban areas: A proposal of an eco-social-green model of the city. Sustainability (Switzerland), 10, 1-22. https://doi.org/10.3390/su10124541

Sturiale, L., Scuderi, A., Timpanaro, G., Foti, V. T., \& Stella, G. (2020). Social and Inclusive "Value" Generation in Metropolitan Area with the "Urban Gardens" Planning. In G. Mondini, A. Oppio, S. Stanghellini, M. Bottero, \& F. Abastante (Eds.), Values and Functions for Future Cities (pp. 285-302). Switzerland: Springer, Cham. https://doi.org/10.1007/978-3030-23786-8_16

UN DESA. (2013). World population prospects: the 2012 revision. (Department of Economic and Social Aff airs, Ed.) (Population). New York: Population Division of the Department of Economic and Social Affairs (DESA) of the United Nations (UN) Secretariat. https://doi.org/10.1016/j.jval.2015.09.940

Wendel, H. E. W., Zarger, R. K., \& Mihelcic, J. R. (2012). Accessibility and usability: Green space preferences, perceptions, and barriers in a rapidly urbanizing city in Latin America. Landscape and Urban Planning, 107, 272-282. https://doi.org/10.1016/j.landurbplan.2012.06.003

Zhang, K. (2014). Understanding Recreational Services of Urban Riverfront Space for Planning Purposes The Case of Tianjin, China. Universität Kassel. 